\title{
The Postoperative Cardiac Function and Complications after Mitral Valve Replacement with Complete Preservation of Subvalvular Apparatus versus Posterior Subvalvular: A Meta Analysis
}

\author{
Zhou Aiming ${ }^{1 *}$, Zeng Shun ${ }^{1}$, Xiao Ruihan ${ }^{1}$, Guo Ke and Liu Daxing ${ }^{1}$ \\ ${ }^{1}$ Department of cardiovascular surgery, the Affiliated Hospital of Zunyi Medical University, Zunyi 563000, china
}

Received: April 02, 2019; Accepted: May 06, 2019; Published: May 09, 2019

*Corresponding author: Zhou Aiming, Department of cardiovascular surgery, the Affiliated Hospital of Zunyi Medical University, Zunyi 563000, china, E-mail:289064279@qq.com

\begin{abstract}
Objective: To systematically evaluate the postoperative cardiac function and complications after mitral valve replacement with complete preservation of subvalvular apparatus versus posterior subvalvular.

Method: The literature of the randomized controlled study, cohort study and case-control study of the two preservation of subvalvular apparatus was searched via the databases of the Pubmed, embase, Cochrane, Web of science, CNKI, Wanfang, CBM, VIP.RevMan5.3 software was used for meta-analysis of outcome indicators evaluation of postoperative cardiac function and postoperative complications.
\end{abstract}

Results: 31 cases of researches were selected, including 17 cases of case-control researches, 11 cases of cohort researches, and 3 cases of randomized controlled trials, with a total of 3468 patients. Left ventricular end diastolic dimension: 6 months after operation, 12 months after operation; Left ventricular end systolic dimension: 6 months after operation, 12 months after operation; Left ventricular ejection fraction: 6 months after operation, 12 months after operation; Early mortality of postoperative, left ventricular rupture, the differences of above outcome indicators between the two groups have statistical significance.

Conclusion: There is no significant difference in after postoperative cardiac function in the short term after mitral valve replacement with complete preservation of subvalvular apparatus versus posterior subvalvular. However, in terms of left ventricular function, long term follow-up shows that the complete preservation of subvalvular apparatus is superior to that of the preservation of posterior subvalvular apparatus. In terms of complications, complete preservation of subvalvular apparatus is superior to preservation of posterior subvalvular apparatus.

Key words: Mitral valve replacement; preservation of subvalvular apparatus; randomized controlled study; cohort study; case control study; Meta analysis.

\section{Introduction}

Standard mitral valve replacement removes all valve leaflets, chordae, and papillary muscles, which disrupts the left ventricular structure and leads to impaire left ventricular function, with the further study of the relationship between submitral valve structure and left ventricular wall in anatomy and physiology. Mitral valve replacement with preservation of the subvalvular apparatus has a protective effect on left ventricular systolic function. However, the reported results of cardiac function and complications after total and partial preservation of subvalvular structures are inconsistent. The purpose of this meta-analysis is to evaluate the difference of cardiac function and complications between the two surgical methods and provide the most powerful basis for guiding clinical surgical decision-making to develop effective treatment methods.

\section{Research Materials and Methods}

\section{Search Strategy}

Search formula ("subvalvular apparatus" OR "subvalvular apparatus" OR "preservation of chordae tendineae" OR "preservation of chordal-sparing") AND ("Mitral Valves" OR "mitral valve" OR "Bicuspid Valve" OR "Bicuspid Valves" Search for Pubmed, embase, Cochrane, Web of science, CNKI, Wanfang, CBM and Weipu. All search strategies are determined by multiple pre-searches. All literature languages were Chinese and English.

\section{Inclusion and Exclusion Criteria}

\section{Inclusion criteria}

1. Patients with valvular disease undergoing mitral valve replacement

2. Randomized control, cohort study, and case-control study of complete subvalvular apparatus and preserved posterior subvalvular

\section{Outcome measures}

? postoperative cardiac function: left ventricular end diastolic diameter, left ventricular end systolic diameter, left ventricular ejection fraction, left ventricular fractional shortening

? Postoperative complications: early postoperative mortality, left ventricular rupture 


\section{Exclusion criteria}

1. Documents from repeated publications of the same study were selected with the most detailed information.

\section{The data could not be extracted.}

\section{Quality Evaluation Criteria}

Two reviewers evaluated the quality of the randomized controlled trials according to the quality evaluation method recommended by the Cochrane systematic review manual [1]. Independent evaluation of literature quality in case-control and cohort studies based on the Newcastle-Ottawa scale [2,3].

\section{Data Extraction}

Formulate a data extraction form and back-to-back extract. The main contents of the extracted data included: general data, research characteristics, exposure factors, follow-up time, research results, and research types.

\section{Statistical Analysis}

Meta-analysis was performed using RevMan5.3 software. The heterogeneity test between the included studies was performed using the $\mathrm{I}^{2}$ test. $\left(\mathrm{I}^{2}<50 \%, P>0.05\right)$ the analysis was performed using a fixed-effect or random-effect model. If there is statistical heterogeneity $\left(\mathrm{I}^{2}>50 \%, P<0.05\right)$, a random effect model was used. After exploring the sources of heterogeneity and eliminating the relatively poor quality literature, sensitivity analysis was conducted again to assess the stability of the merged results. Qualitative analysis of publication bias of funnel charts was performed for more than 10 studies with outcomes.

\section{Research Results}

\section{Literature Screening Results}

The literature screening flow chart was shown in Figure 1.

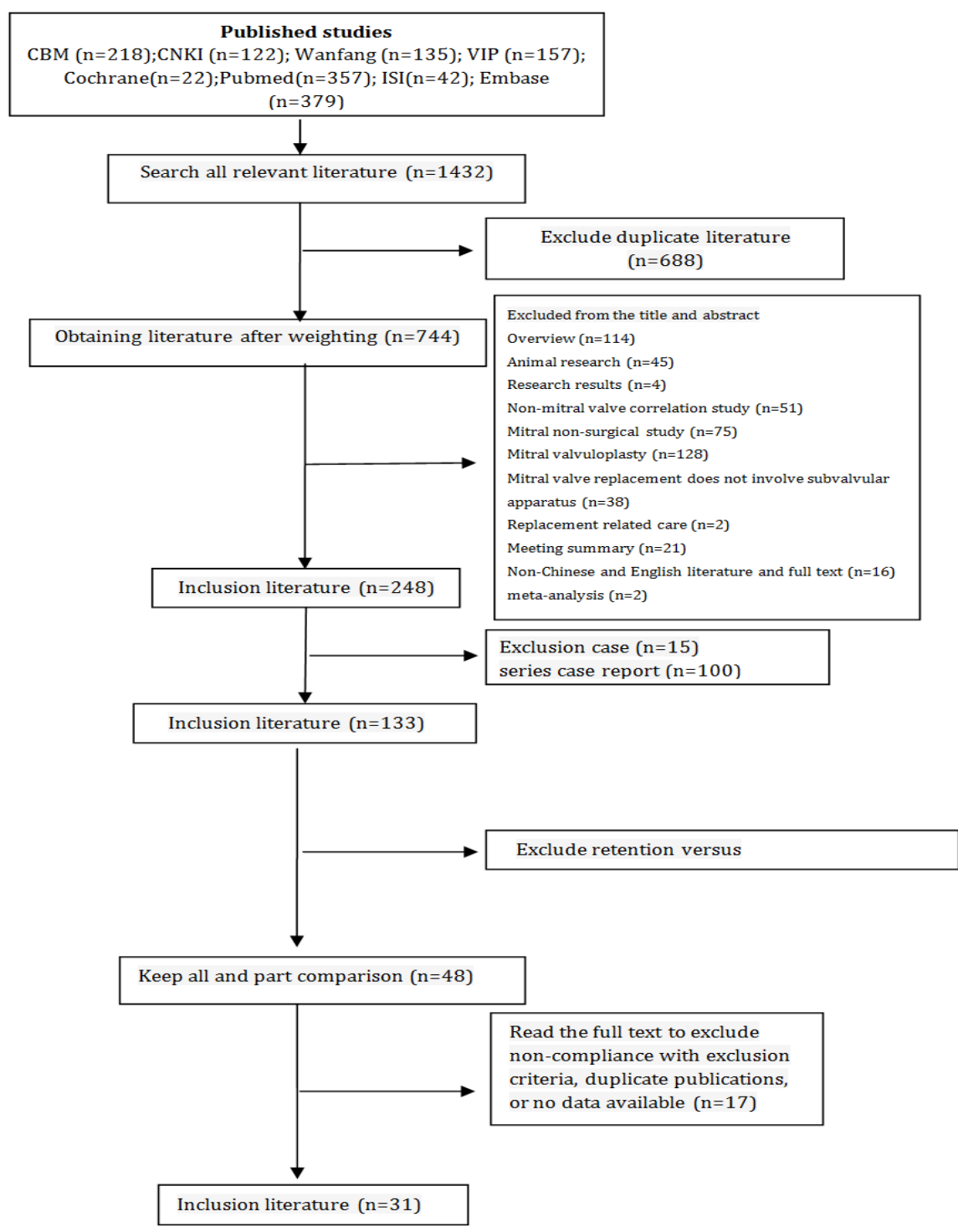

Figure 1: Literature screening flow chart 


\section{Basic Characteristics of the Included Studies}

A total of 17 case-control studies were included, all of which were retrospective studies, including 1096 patients in the experimental group and 1554 patients in the control group. A total of 11 cohort studies were included, all of which were prospective studies, including 291 patients in the trial group and 407 patients in the control group, 3 randomized controlled trials, including 67 patients in the experimental group and 53 patients in the control group. The postoperative cardiac function indexes and postoperative complications were shown in Table 1.

\section{Quality Evaluation of the Included Studies}

According to the Newcastle-Ottawa Scale (NOS), the cohort study and case-control study literature were evaluated according to the type of study with Methodological Quality Assessment, the quality evaluation method recommended by the Cochrane System Evaluation Manual, use for the quality of the literature of randomized controlled trials was evaluated in Table $2-4$.

\begin{tabular}{|c|c|c|c|c|c|c|c|c|c|c|c|c|}
\hline \multirow{2}{*}{$\begin{array}{c}\text { Author and } \\
\text { publication date }\end{array}$} & \multicolumn{9}{|c|}{ Research object } & \multirow{2}{*}{$\begin{array}{l}\text { Follow- } \\
\text { up time }\end{array}$} & \multirow{2}{*}{$\begin{array}{l}\text { Research } \\
\text { result }\end{array}$} & \multirow{2}{*}{$\begin{array}{c}\text { Research } \\
\text { type }\end{array}$} \\
\hline & Country & P1 & P2 & P3 & $\mathbf{E}$ & C & $\mathbf{M}$ & $\mathbf{F}$ & mean age / age group & & & \\
\hline Hassouna1998 [4] & Britain & 96 & - & - & 36 & 60 & 40 & 56 & $23.2 \pm 1.12 / 25.7 \pm 0.71$ & $6 \mathrm{~m}$ & 01,02 & cohort study \\
\hline SunWenyu1999 [5] & China & 17 & - & - & 9 & 8 & 6 & 11 & $43 \pm 6 / 39 \pm 8$ & $3 \mathrm{~m}$ & 02 & Case study \\
\hline PanCuizhen2000 [6] & China & - & - & - & 8 & 10 & 9 & 9 & $41.78 \pm 10.99 / 35.75 \pm 11.12$ & $3 m$ & 01 & cohort study \\
\hline Shuxianhong2000 [7] & China & - & - & - & 8 & 10 & - & - & $41.78 \pm 10.99 / 35.5 \pm 11.12$ & $3 m$ & 01,02 & cohort study \\
\hline $\begin{array}{c}\text { Wangminsheng } 2000 \\
{[8]}\end{array}$ & China & 9 & 8 & 5 & 11 & 11 & 11 & 11 & $41.78 \pm 10.99 / 35.75 \pm 11.12$ & $10 \mathrm{~d}$ & 01,02 & cohort study \\
\hline Yun,K.L.2002 [9] & California & 3 & 31 & 2 & 21 & 15 & 19 & 17 & $56 \pm 13 / 59 \pm 11$ & $12 \mathrm{~m}$ & 01 & $\begin{array}{c}\text { Randomized } \\
\text { control }\end{array}$ \\
\hline $\begin{array}{c}\text { ZhangChunxi2003 } \\
{[10]}\end{array}$ & China & - & - & - & 14 & 15 & - & - & $21-58$ & $6,12 \mathrm{~m}$ & 01 & Case control \\
\hline ZhongLing2003 [11] & China & - & - & - & 25 & 25 & 19 & 31 & $38.7 \pm 10.5 / 40.2 \pm 11.2$ & $3,6 \mathrm{~m}$ & 01 & Case control \\
\hline $\begin{array}{c}\text { MengGuowei2004 } \\
\text { [12] }\end{array}$ & China & 54 & - & - & 35 & 19 & 29 & 25 & $40.31 \pm 12.17 / 42.32 \pm 17.74$ & $6 \mathrm{~m}$ & 01,03 & Case control \\
\hline $\begin{array}{c}\text { PanTiecheng2004 } \\
{[13]}\end{array}$ & China & 37 & 7 & - & 26 & 18 & 17 & 27 & $19-56$ & $3,6 \mathrm{~m}$ & $01,02,03$ & $\begin{array}{c}\text { Randomized } \\
\text { control }\end{array}$ \\
\hline Chowdhury2005 [14] & India & 381 & - & - & 257 & 124 & 240 & 141 & $35 \pm 23 / 33.0 \pm 19.0$ & $4 y$ & 01,03 & Case control \\
\hline Muthialu2005 [15] & India & 58 & - & 40 & 22 & 76 & 44 & 54 & $18-61$ & $6 \mathrm{~m}$ & $01,02,03$ & Case control \\
\hline $\begin{array}{c}\text { ChenShengxi } 2005 \\
{[16]}\end{array}$ & China & 97 & - & - & 42 & 55 & 34 & 63 & $\begin{array}{c}40.02 \pm 13.37 / 44.11 \\
\pm 10.74\end{array}$ & $6 \mathrm{~m}$ & $01,02,03$ & cohort study \\
\hline Chowdhury2006[17] & India & - & - & - & 34 & 56 & 53 & 57 & $30.86 \pm 10.3 / 31.58 \pm 8.28$ & $12 \mathrm{~m}$ & $01,02,03$ & cohort study \\
\hline WangLong2008 [19] & China & - & - & - & 30 & 28 & - & - & $17-68$ & $6,12 \mathrm{~m}$ & 01 & Case control \\
\hline ZhouFang2008 [20] & China & 56 & - & - & 26 & 30 & 22 & 34 & $18-64$ & $6 \mathrm{~m}$ & $01,02,03$ & Case control \\
\hline Garcia2008 [21] & Spain & - & - & - & 162 & 248 & 121 & 289 & $61 \pm 10 / 62 \pm 9$ & $6 \mathrm{~m}$ & $01,02,03$ & Case control \\
\hline Zakai2010 [22] & Pakistan & - & - & - & 36 & 54 & 27 & 63 & $42.19 \pm 15.14 / 39.28 \pm 15.68$ & $6 \mathrm{~m}$ & $01,02,03$ & cohort study \\
\hline GuoYong2011[23] & China & 50 & - & - & 20 & 30 & 18 & 32 & $\begin{array}{c}46.52 \pm 12.34 / 47.35 \\
\pm 11.86\end{array}$ & $6 \mathrm{~m}$ & 01 & Case control \\
\hline Garcia 2011[24] & Spain & 601 & 135 & 65 & 206 & 595 & 240 & 561 & $61.4 \pm 10.4 / 61.4 \pm 10.7$ & $12 \mathrm{~m}$ & 01,03 & Case control \\
\hline $\begin{array}{c}\text { XuanHaiyang2012 } \\
\text { [25] }\end{array}$ & China & 21 & 10 & - & 17 & 14 & 19 & 12 & $65-73$ & $6 \mathrm{~m}$ & $01,02,03$ & Case control \\
\hline LiangKe2012 [26] & China & - & - & - & 33 & 38 & - & - & & $6 \mathrm{~m}$ & 01 & Case control \\
\hline Chen,L.2013 [27] & China & 128 & - & - & 58 & 70 & 46 & 82 & $40.8 \pm 5.3 / 41.7 \pm 16.1$ & $3,12 \mathrm{~m}$ & $01,02,03$ & Case control \\
\hline
\end{tabular}

Citation: Zhou Aiming, Zeng Shun, Xiao Ruihan, et al. (2019) The Postoperative Cardiac Function and Complications after Mitral Valve Replacement with Complete Preservation of Subvalvular Apparatus versus Posterior Subvalvular: A Meta Analysis. Cardiovascular Thoracic Surgery 4(2):1-10. DOI: 10.15226/2573-864X/4/2/00159 
The Postoperative Cardiac Function and Complications after Mitral Valve

Posterior Subvalvular: A Meta Analysis

\begin{tabular}{|c|c|c|c|c|c|c|c|c|c|c|c|c|}
\hline Ozdemir.2014 [28] & Turkey & 18 & 52 & - & 16 & 54 & 49 & 21 & $56.5 \pm 13.1 / 52.55 \pm 13.9$ & $6 \mathrm{~m}$ & 01 & cohort study \\
\hline Roshanali2014 [29] & Iran & - & - & - & 20 & 20 & - & - & & $6 \mathrm{~m}$ & 01 & $\begin{array}{c}\text { Randomized } \\
\text { control }\end{array}$ \\
\hline LiJiyong2014 [30] & China & 78 & 17 & 7 & 102 & 102 & 103 & 101 & $46.0 \pm 10.1 / 47 \pm 9.2$ & $6 \mathrm{~m}$ & 01,03 & Case study \\
\hline $\begin{array}{c}\text { ZhangYulong2014 } \\
{[31]}\end{array}$ & China & 84 & - & - & 42 & 42 & 33 & 49 & $43.28 \pm 7.42$ & $3 w$ & 01,02 & cohort study \\
\hline $\begin{array}{c}\text { HuangXiaolong2015 } \\
\text { [32] }\end{array}$ & China & 53 & 14 & 8 & 32 & 30 & 31 & 44 & $48.13 \pm 10.84 / 47.82 \pm 9.73$ & $6 \mathrm{~m}$ & $01,02,03$ & Case control \\
\hline RenFei2016 [33] & China & - & - & - & 48 & 102 & 46 & 104 & $22-75$ & $3 \mathrm{~m}$ & $01,02,03$ & Case control \\
\hline LinLonghui2017 [34] & China & 45 & 23 & 16 & 42 & 42 & 49 & 35 & $47.7 \pm 10.4 / 47.6 \pm 10.3$ & $12 \mathrm{~m}$ & 01,03 & cohort study \\
\hline
\end{tabular}

Table 2: Bias Risk Feature table (Randomized controlled study)

\begin{tabular}{|c|c|c|c|c|c|c|}
\hline $\begin{array}{c}\text { Author and } \\
\text { publication date }\end{array}$ & $\begin{array}{c}\text { random } \\
\text { Method }\end{array}$ & $\begin{array}{c}\text { Allocation } \\
\text { concealment }\end{array}$ & $\begin{array}{c}\text { Blind } \\
\text { method }\end{array}$ & $\begin{array}{c}\text { Integrity of } \\
\text { Outcome Data }\end{array}$ & $\begin{array}{c}\text { Selective reporting the } \\
\text { research findings }\end{array}$ & Other bias \\
\hline Roshanali2014 [29] & Unclear & Unclear & Unclear & complete & no & Unclear \\
\hline Yun, K. L.2002 [9] & Unclear & Unclear & Unclear & complete & no & Unclear \\
\hline $\begin{array}{c}\text { PanTiecheng2004 } \\
\text { [13] }\end{array}$ & Unclear & Unclear & Unclear & loss to follow-up & no & Unclear \\
\hline
\end{tabular}

Table 3: Bias Risk Feature table (cohort study)

\begin{tabular}{|c|c|c|c|c|c|c|c|c|c|}
\hline \multirow[b]{2}{*}{$\begin{array}{c}\text { Author and publication } \\
\text { date }\end{array}$} & \multicolumn{5}{|c|}{ The selection of study population } & \multicolumn{3}{|c|}{ Result measurement } & \multirow[b]{2}{*}{ Score } \\
\hline & (1) & (2) & (3) & (4) & (5) & (6) & (7) & (8) & \\
\hline Chowdhury2006 [14] & 1 & 1 & 1 & 1 & 1 & 1 & 1 & 0 & 7 \\
\hline Hassouna1998 [4] & 1 & 1 & 1 & 1 & 1 & 1 & 1 & 0 & 7 \\
\hline Ozdemir.2014 [28] & 1 & 1 & 1 & 1 & 1 & 1 & 1 & 1 & 8 \\
\hline Zakai2010 [22] & 1 & 1 & 1 & 1 & 1 & 1 & 1 & 0 & 7 \\
\hline ChenShengxi2005 [16] & 1 & 1 & 1 & 1 & 1 & 1 & 1 & 0 & 7 \\
\hline LinLonghui2017 [34] & 1 & 1 & 1 & 1 & 1 & 1 & 1 & 1 & 8 \\
\hline PanCuizhen2000 [6] & 1 & 1 & 1 & 1 & 1 & 1 & 1 & 1 & 8 \\
\hline ShuXianhong2000 [7] & 1 & 1 & 1 & 1 & 1 & 1 & 1 & 1 & 8 \\
\hline WangMinsheng2000 [8] & 1 & 1 & 1 & 1 & 1 & 1 & 1 & 0 & 7 \\
\hline ZhangChunxi2006 [18] & 1 & 1 & 1 & 1 & 1 & 1 & 1 & 1 & 8 \\
\hline ZhangYulong2014 [31] & 1 & 1 & 1 & 1 & 1 & 1 & 1 & 1 & 8 \\
\hline
\end{tabular}

Citation: Zhou Aiming, Zeng Shun, Xiao Ruihan, et al. (2019) The Postoperative Cardiac Function and Complications after Mitral

Valve Replacement with Complete Preservation of Subvalvular Apparatus versus Posterior Subvalvular: A Meta Analysis.

Cardiovascular Thoracic Surgery 4(2):1-10. DOI: 10.15226/2573-864X/4/2/00159 
The Postoperative Cardiac Function and Complications after Mitral Valve

Posterior Subvalvular: A Meta Analysis

Table 4: Bias Risk Feature table (Case control)

\begin{tabular}{|c|c|c|c|c|c|c|c|c|c|}
\hline \multirow{2}{*}{ Author and publication date } & \multicolumn{5}{|c|}{ The selection of study population } & \multicolumn{3}{|c|}{ Result measurement } & \multirow{2}{*}{ Score } \\
\hline & (1) & (2) & (3) & (4) & (5) & (6) & (7) & (8) & \\
\hline Chen, L .2013 [27] & 1 & 1 & 1 & 1 & 1 & 1 & 1 & 1 & 8 \\
\hline Chowdhury2005 [14] & 1 & 1 & 1 & 1 & 1 & 1 & 1 & 0 & 7 \\
\hline Garcia2011 [24] & 1 & 1 & 1 & 1 & 1 & 1 & 1 & 1 & 8 \\
\hline Garcia2008 [21] & 1 & 1 & 1 & 1 & 1 & 1 & 1 & 1 & 8 \\
\hline Muthialu2005 [15] & 1 & 1 & 1 & 1 & 1 & 1 & 1 & 0 & 7 \\
\hline GuoYong2011 [23] & 1 & 1 & 1 & 1 & 1 & 1 & 1 & 1 & 8 \\
\hline RenFei2016 [33] & 1 & 1 & 1 & 1 & 1 & 1 & 1 & 0 & 7 \\
\hline WangLong2008 [19] & 1 & 1 & 1 & 1 & 1 & 1 & 1 & 1 & 8 \\
\hline XuanHaiyang2012 [25] & 1 & 1 & 1 & 1 & 1 & 1 & 1 & 1 & 8 \\
\hline ZhangChunxi2003 [10] & 1 & 1 & 1 & 1 & 1 & 1 & 1 & 1 & 8 \\
\hline ZhongLing2003 [11] & 1 & 1 & 1 & 1 & 1 & 1 & 1 & 1 & 8 \\
\hline ZhouFang2008 [20] & 1 & 1 & 1 & 1 & 1 & 1 & 1 & 1 & 8 \\
\hline LiangKe2012 [26] & 1 & 1 & 1 & 1 & 1 & 1 & 1 & 1 & 8 \\
\hline MengGuowei2004 [12] & 1 & 1 & 1 & 1 & 1 & 1 & 1 & 0 & 7 \\
\hline HuangXiaolong2015 [32] & 1 & 1 & 1 & 1 & 1 & 1 & 1 & 1 & 8 \\
\hline Sunwenyu1999 [5] & 1 & 1 & 1 & 1 & 1 & 1 & 1 & 0 & 7 \\
\hline Lijiyong2014 [30] & 1 & 1 & 1 & 1 & 1 & 1 & 1 & 1 & 8 \\
\hline
\end{tabular}

(1)appropriate Case determination; (2)Representativeness of cases; (3)Contrast selection; (4)Confirmation of Contrast; (5)Intergroup comparability; (6)Determination of Exposure Factors; (7)same method to determine the exposures of cases and control groups; (8) Noresponse rate

\section{Meta Analysis Results}

\section{Left Ventricular End Diastolic Diameter}

\section{Postoperative 6 Months}

The combined effect of the two groups [SMD $=-0.65,95 \% \mathrm{CI}$ $(-1.09,-0.22), \mathrm{P}=0.003]$, the random effect model meta-analysis showed statistically significant differences, indicating that the complete retention of the subvalvular apparatus group was better than the posterior subvalvular group. 11 case-control studies were included. There was significant difference between the two groups after the combined effect. Five cohort studies were included, and there was no statistically significant difference after the combined effect between the two groups. Two randomized controlled trials were included, and there was no statistically significant difference after the combined effect between the two groups Figure 2.

\section{Postoperative 12 Months}

The combined effect of the two groups [SMD $=-0.88,95 \% \mathrm{CI}$ $(-1.42,-0.35), \mathrm{P}=0.001]$, the random effect model meta-analysis showed statistical differences, The results showed that the complete preservation of subvalvular apparatus group was superior to the preservation of posterior subvalvular structure group. Four case-control studies were included, and the combined effect of the two groups showed statistically significant differences. Two cohort studies were included, and the difference between the two groups showed statistically significant differences. A randomized controlled trial was included and the difference was not statistically significant Figure 3.

The meta-analysis results of left ventricular ejection fraction at Postoperative 6 months, left ventricular ejection fraction at Postoperative 12 months, left ventricular ejection fraction at Postoperative 6 months, left ventricular ejection fraction at Postoperative 12 months, left ventricular fractional shortening at Postoperative 6 months, early postoperative mortality, left ventricular rupture have statistical significance Table 5. 
The Postoperative Cardiac Function and Complications after Mitral Valve

Posterior Subvalvular: A Meta Analysis

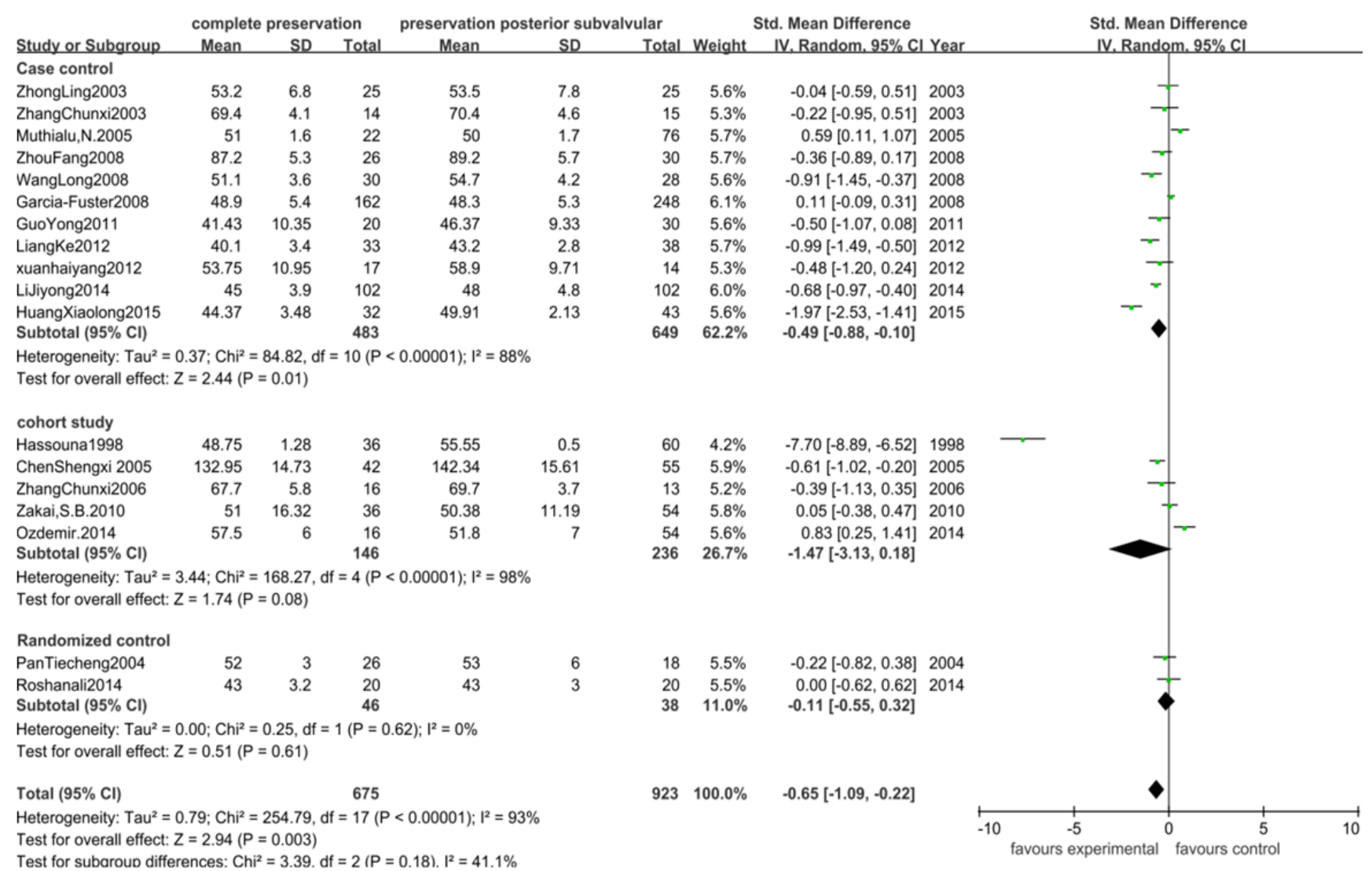

Figure 2: Meta-Analysis of left ventricular end-diastolic diameters at Postoperative 6 months

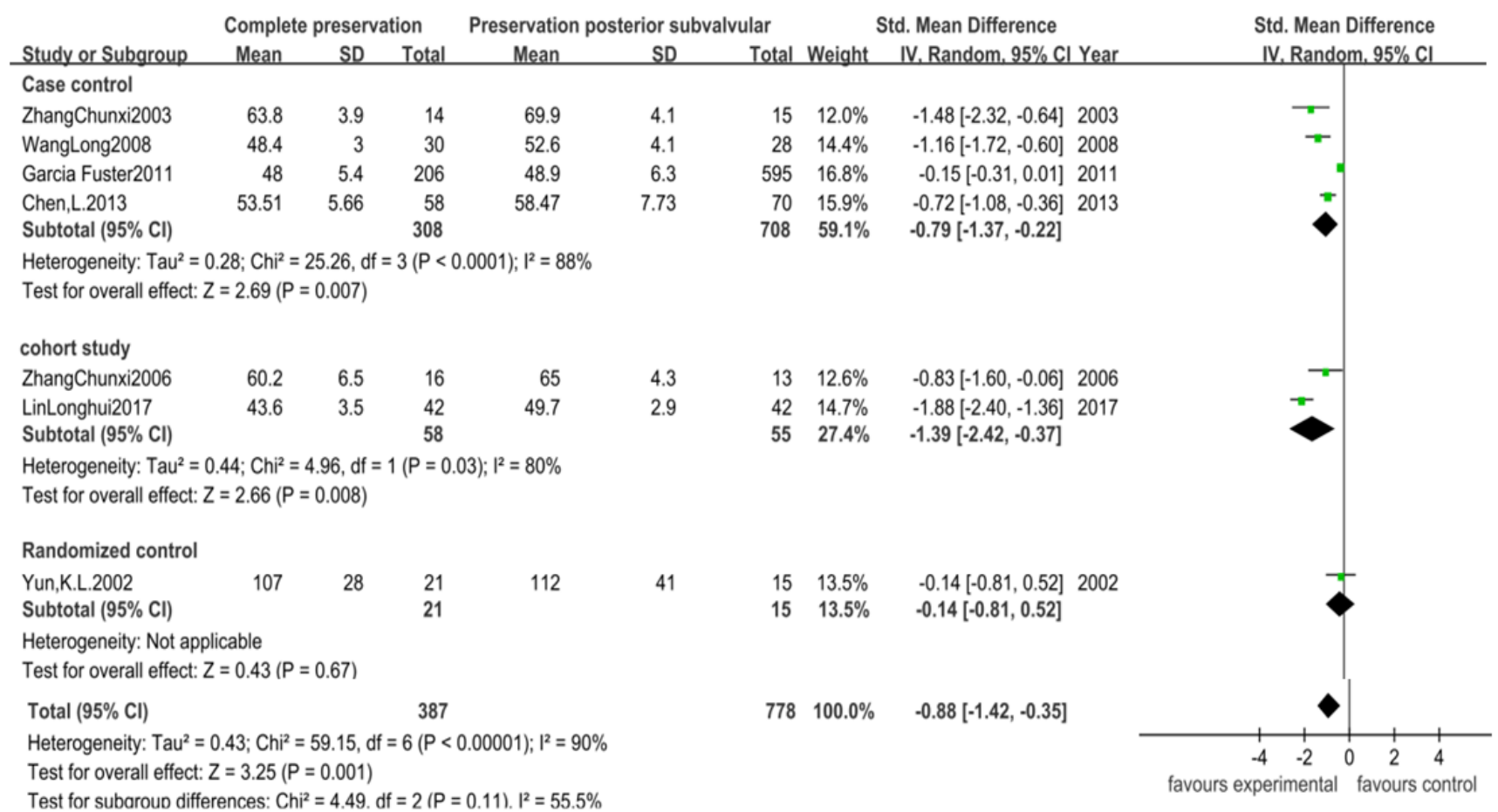

Figure 3: Meta-Analysis of left ventricular end-diastolic diameters at Postoperative 12 months

Citation: Zhou Aiming, Zeng Shun, Xiao Ruihan, et al. (2019) The Postoperative Cardiac Function and Complications after Mitral Page 6 of 10 Valve Replacement with Complete Preservation of Subvalvular Apparatus versus Posterior Subvalvular: A Meta Analysis.

Cardiovascular Thoracic Surgery 4(2):1-10. DOI: 10.15226/2573-864X/4/2/00159 
The Postoperative Cardiac Function and Complications after Mitral Valve

Posterior Subvalvular: A Meta Analysis

Table 5: Meta-analysis results of cardiac function and complications between the two groups (Figure S1-5)

Table 5a: cardiac function

\begin{tabular}{|c|c|c|c|c|c|c|c|}
\hline Outcomes & Trials & E (Total) & C (Total) & SM & SMD $\backslash 95 \% C I$ & $\mathbf{I}^{2}$ & $\mathbf{P}$ \\
\hline $\begin{array}{c}\text { left ventricular end systolic } \\
\text { diameter }(6 \mathrm{M})\end{array}$ & 18 & 675 & 923 & REM & $-0.66[-1.16,-0.15]$ & 95 & 0.01 \\
\hline $\begin{array}{c}\text { left ventricular end systolic } \\
\text { diameter }(12 \mathrm{M})\end{array}$ & 5 & 123 & 113 & REM & $-1.12[-1.84,-0.6]$ & 77 & 0.0001 \\
\hline $\begin{array}{l}\text { left ventricular ejection } \\
\text { fraction }(6 \mathrm{M})\end{array}$ & 14 & 596 & 800 & REM & $0.83[0.29,1.37]$ & 95 & 0.002 \\
\hline $\begin{array}{l}\text { left ventricular ejection } \\
\text { fraction }(12 \mathrm{M})\end{array}$ & 7 & 426 & 825 & REM & $0.64[0.26,1.02]$ & 84 & 0.001 \\
\hline $\begin{array}{c}\text { left ventricular fractional } \\
\text { shortening }(6 \mathrm{M})\end{array}$ & 11 & 434 & 608 & REM & $-0.15[-0.57,0.27]$ & 89 & 0.48 \\
\hline
\end{tabular}

Table 5b: complications

\begin{tabular}{|c|c|c|c|c|c|c|c|}
\hline Outcomes & Trials & E(Events/Total) & C(Events/Total) & SM & RR,95\%CI & I & P \\
\hline early postoperative mortality & 14 & $30 / 1071$ & $81 / 1566$ & REM & $0.59[0.39,0.91]$ & 0 \\
\hline left ventricular rupture & 3 & $0 / 176$ & $9 / 187$ & REM & $0.16[0.03,0.93]$ & 0 \\
\hline
\end{tabular}

E: Experimental group, C: Control group, SM: statistic method, RR: relative risk, CI: confidence interval; REM, random-effects model, M: months

\section{Publishing Bias}

The left ventricular end-diastolic diameter, the left ventricular end-systolic diameter, early postoperative mortality were included in more than 10 case-control studies in Postoperative 6 months and the funnel plot analysis was published. The results showed that the studies were distributed in the funnel. The two sides were basically symmetrical. A few studies were located outside the funnel, this suggests that the publication bias of this study may be small.

\section{Sensitivity Analysis}

Excluding the outside of the funnel plot and the study with poor quality of the index, left ventricular end-diastolic diameter and left ventricular end-systolic diameter postoperative 6 months, The results of each outcome index did not reverse, suggesting that the results were stable Table 6.
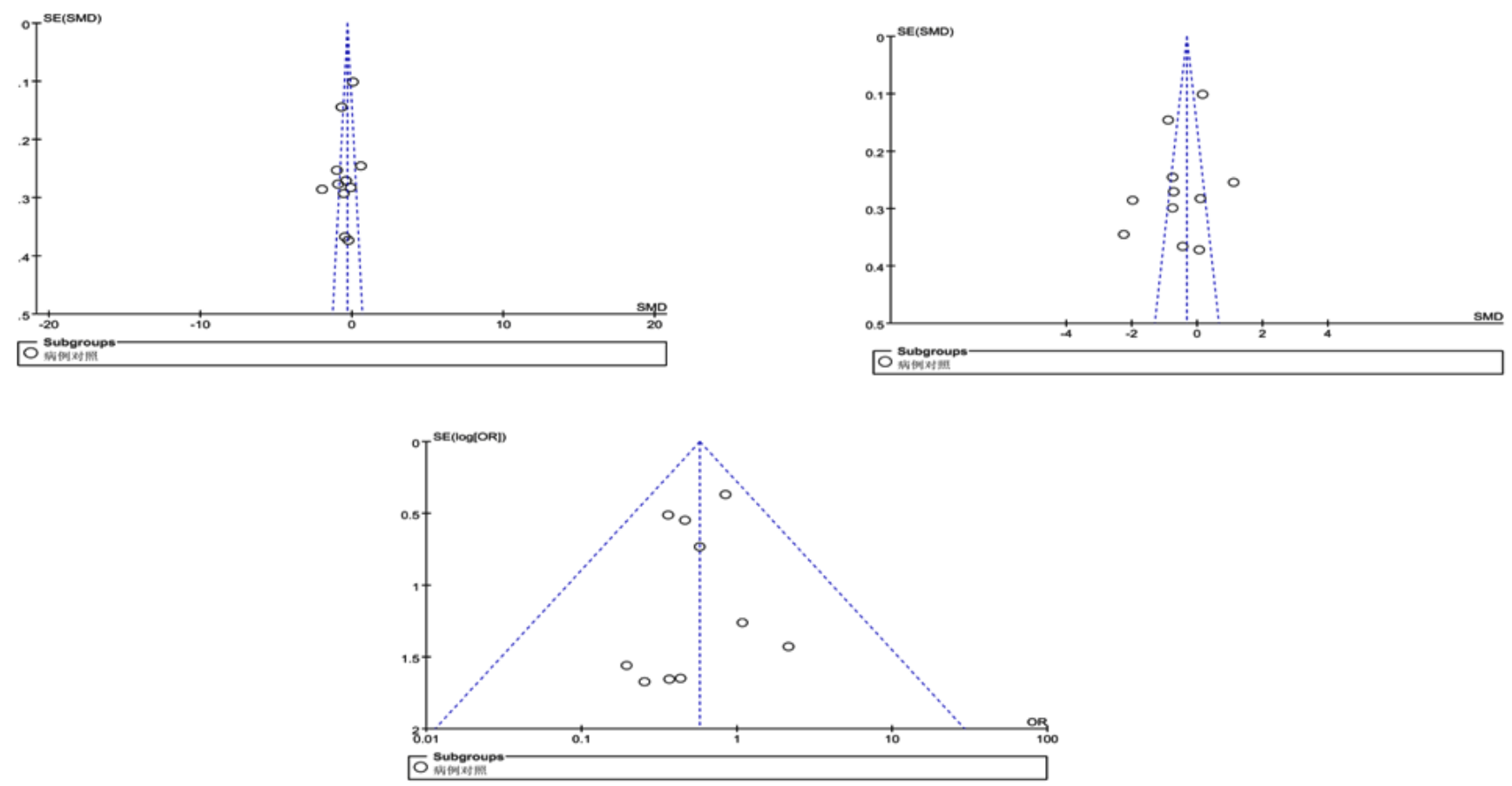

Citation: Zhou Aiming, Zeng Shun, Xiao Ruihan, et al. (2019) The Postoperative Cardiac Function and Complications after Mitral Valve Replacement with Complete Preservation of Subvalvular Apparatus versus Posterior Subvalvular: A Meta Analysis. 
The Postoperative Cardiac Function and Complications after Mitral Valve

Posterior Subvalvular: A Meta Analysis

\begin{tabular}{|c|c|c|c|c|c|c|}
\hline \multirow[b]{2}{*}{ Outcome indicators } & \multirow[b]{2}{*}{ Analysis type } & \multirow{2}{*}{$\begin{array}{l}\text { Research } \\
\text { quantity }\end{array}$} & \multicolumn{2}{|c|}{ Heterogeneity } & \multicolumn{2}{|c|}{ Effectiveness Estimates } \\
\hline & & & $P$ & $I^{2}$ value & $\begin{array}{l}\text { MD/SMD } \\
(95 \% \mathrm{CI})\end{array}$ & $\mathbf{P}$ 值 \\
\hline \multirow{2}{*}{$\begin{array}{l}\text { Left ventricular end diastolic } \\
\text { diameter postoperative } 6 \text { months }\end{array}$} & Case control & 11 & $<0.00001$ & $88 \%$ & $-0.49(-0.88,0.1)$ & 0.01 \\
\hline & Sensitivity analysis \#1 & 8 & 0.19 & $30 \%$ & $\begin{array}{c}-0.57(-0.79,0.35 \\
)\end{array}$ & $<0.00001$ \\
\hline \multirow{2}{*}{$\begin{array}{l}\text { Left ventricular end systolic diameter } \\
\text { postoperative } 6 \text { months }\end{array}$} & Case control & 11 & $<0.00001$ & $93 \%$ & $\begin{array}{c}-0.56(-1.07,0.05 \\
)\end{array}$ & 0.03 \\
\hline & Sensitivity analysis \#2 & 6 & 0.12 & $43 \%$ & $\begin{array}{c}-0.46(-0.7,-0.23 \\
)\end{array}$ & 0.0001 \\
\hline \multicolumn{7}{|c|}{ \#1References excluded from Sensitivity Analysis [16,22,33] } \\
\hline
\end{tabular}

\section{Discussion}

Complete preservation of the mitral valve leaflet and subvalvular apparatus and retention of the posterior leaflet and its subvalvular apparatus are two surgical methods for mitral valve replacement retaining the subvalvular apparatus. Current studies on cardiac function and complications due to different preservation of subvalvular apparatus are inconsistent. This article mainly expands the sample size, which improves the effect quantity estimation and makes the conclusion more comprehensive and accurate, so as to evaluate the difference of postoperative cardiac function and complications between the two surgical methods. Thirty-one studies were included; a total of 3468 patients, 17 case-control studies, 11 cohort studies and 3 randomized controlled studies.

The main indicators of this systematic evaluation include postoperative cardiac function indicators and complications. In terms of left ventricular end-diastolic diameter, left ventricular end-systolic diameter and left ventricular ejection fraction, the combined effect of postoperative 6 and 12 months showed that the complete preservation of subvalvular apparatus group was superior to the preservation of posterior subvalvular apparatus group. In terms of left ventricular fractional shortening, there was no statistical difference between the two surgical methods postoperative 6 months. In terms of postoperative complications, the combined effect of postoperative early mortality and left ventricular rupture showed that the fully preserved subvalvular apparatus was lower than the retained posterior subvalvular apparatus.

SáMPBDO et [35] performed a meta-analysis of the structure of fully preserved and partially preserved mitral valve structures. A total of 1535 patients in eight research centers were included. Data of 30-day mortality, low cardiac output syndrome and left ventricular ejection fraction were extracted and analyzed. Finally, there was no statistical difference. There were no significant differences in 30-day mortality, low cardiac output syndrome and left ventricular ejection fraction between the complete preservation and posterior subvalvular apparatus. This article only included data from 8 foreign research centers, which was not included in the Chinese data study, the results of early postoperative mortality and left ventricular ejection fraction were inconsistent. The literature included in this paper was the data of several national research centers. The sample size of the included literature was larger. The outcomes of the extraction included: postoperative left ventricular end diastolic diameter, left ventricular end systolic diameter, left ventricular ejection fraction, Early postoperative mortality and left ventricular rupture made the outcome indicators more comprehensive, the evaluation was more adequate, and the evidence was more reliable.

According to the systematic review, the two surgical methods showed that the complete preservation was superior to the retained posterior subvalvular apparatus after longterm follow-up. The postoperative complications of the fully preserved subvalvular apparatus were better than the posterior subvalvular apparatus. Therefore, for patients undergoing mitral valve replacement, it is suggested that the surgical procedure of the complete preservation of subvalvular apparatus should be selected under the same conditions. Which preserves the normal physiological structure of the heart, maintains the left heart function, and reduces postoperative complications.

The overall quality of this paper is fine. Random effect models are used in all cases. The meta-analysis of more than 10 studies has done a funnel plot for publication bias analysis. The comprehensive analysis shows that the meta-analysis results are scientific and reliable. For the outcome Indicators, the sensitivity analysis was carried out. After excluding the outside of funnel diagram and the poor quality of research, the results were not reversed, which showed that the results were stable.

The limitations of this study, Some of the studies included in the literature have a small sample size, meanwhile the casecontrol study are retrospective studies, the existence of recall information bias and confounding factors, which will affect the 
authenticity of the meta-analysis results, it is recommended that Prospective cohort studies and randomized controlled trials should be performed to improve the quality of the study. Are there racial and regional differences in the studies included in the literature for many countries. Because of the lack of longer followup data in the included literature, it is impossible to evaluate the results of longer follow-up.

In summary, long-term follow-up of mitral valve replacement showed that complete preservation of subvalvular structure was superior to preservation of posterior subvalvular structure in left ventricular function and complications. In view of the limitations of this systematic review, more high-quality and large-sample prospective studies are expected to provide more reliable evidence for the clinic.

\section{References}

1. Zeng Xiantao, Bao Cuiping, Cao Shiyi, et al. Meta Analysis Series III: Quality Evaluation Tool for Randomized Controlled Trials [J]. Chinese Journal of Evidence-Based Cardiovascular Medicine. 2012,4(3):183185.

2. Stang A. Critical evaluation of the Newcastle-Ottawa scale for the assessment of the quality of nonrandomized studies in meta-analyses [J]. European Journal of Epidemiology. 2010;25(9):603-605.

3. Wells G A, Shea B J, O'Connell D, et al. The Newcastle-Ottawa Scale (NOS) for Assessing the Quality of Non-Randomized Studies in MetaAnalysis [J]. Applied Engineering in Agriculture. 2012;18(6):727-734.

4. Hassouna A, Elmahalawy N. Valve replacement in rheumatic mitral incompetence: total versus posterior chordal preservation [J]. Cardiovasc Surg. 1998;6(2):133-138.

5. Sun Wenyu, Li Shouxian, Song Huimin. Effects of mitral valve replacement with or without preservation of subvalvular structures on early hemodynamics [J]. Chinese Journal of Thoracic and Cardiovascular Surgery. 1999;6(2):77-79.

6. Pan Cuizhen, Shu Xianhong, Shen Xuedong, et al. Ultrasound evaluation of the effect of mitral valve replacement resection or preservation of subvalvular structure on left ventricular geometry [J]. Chinese Journal of Ultrasound Medicine. 2000;16(10): 748-751.

7. Shu Xianhong, Pan Cuizhen. Acoustic quantitative evaluation of left ventricular function after mitral valve replacement with preservation of subvalvular structure [J]. Chinese Journal of Ultrasound Imaging 2000;9(10): 592-595.

8. Yu Ang, Wang Minsheng, Wang Chunsheng, et al. The importance of preserving the subvalvular structure in mitral valve replacement to maintain the geometric shape of the left ventricle at the early stage after operation [J]. Chinese Journal of Cardiology. 2000(3):150-154.

9. Yun KL, Sintek CF, Miller DC, Pfeffer TA, Kochamba GS, Khonsari S et al. Randomized trial comparing partial versus complete chordalsparing mitral valve replacement: effects on left ventricular volume and function [J]. J Thorac Cardiovasc Surg. 2002;123(4):707-714.

10.Zhang Chunxi, Huang Dade. Effects of partial or total mitral valve replacement with preservation of subvalvular structure on the geometry of giant left ventricle [J]. Lingnan Journal of Cardiovascular Disease. 2003;9(6):387-389.

11.Zhong Ling, Chen Liangwan, Lin Feng, et al. Short-term clinical observation of echocardiography in mitral valve replacement resection or preservation of subvalvular structures [J]. Chinese Journal of Ultrasound Diagnosis. 2003;4(5):338-340.

12. Meng Guowei, Sun Qiang, Cao Yanxia, et al. Mitral valve replacement with preservation of subvalvular structures [J]. Chinese Clinical Journal of Thoracic and Cardiovascular Surgery. 2004;11(3):228-230.

13. Pan Tiecheng, Zhang Nei, Pan Youmin, et al. Clinical study of mitral valve replacement with preservation of partial or total subvalvular structure [J]. Orthopedics. 2004;28(6):381-382.

14. Chowdhury UK, Kumar AS, Airan B, et al. Mitral Valve Replacement With and Without Chordal Preservation in a Rheumatic Population: Serial Echocardiographic Assessment of Left Ventricular Size and Function [J]. Ann Thorac Surg. 2005;79(6):1926-1933.

15. Muthialu N, Varma S K, Ramanathan S, et al. Effect of chordal preservation on leftventricular function [J]. Asian Cardiovasc Thorac Ann, 2005;13(3):233-237.

16. Chen Shengxi, Zhe Erping, Longlong, et al. "Button-like" chordae tendineae transfer for mitral valve replacement with preservation of total subvalvular structure [C]. Proceedings of the National Conference on Cardiac Valve Surgery. 2005.

17. Chowdhury UK, Venkataiya JK, Patel CD, et al. Serial radionuclide angiographic assessment of left ventricular ejection fraction and regional wall motion after mitral valve replacement in patients with rheumatic disease [J]. Am Heart J. 2006;152(6):1201-1207.

18. Zhang Chunxi.A comparative study on the morphological and functional recovery of giant left ventricle after mitral valve replacement with partial or total preservation of subvalvular structure [D]. Guangzhou Medical College; Guangzhou Medical University, 2006.

19.Wang Long, Li Baijun, Hu Yichao, et al. Observation of long-term and medium-term clinical effects of mitral valve replacement with preservation of subvalvular structure [J]. Chinese Journal of Misdiagnosis. 2008;8 (30):7385-7386.

20.Zhou Fang, Chen Shengxi, Luo Wanjun, et al. The effect of "Button-like" mitral valve replacement with preservation of subvalvular structure on left ventricular function [J]. Journal of Applied Medicine. 2008;24 (23):4031-4033.

21. García-Fuster R, Estevez V, Gil 0, et al. Mitral Valve Replacement in Rheumatic Patients: Effects of Chordal Preservation[J]. Ann Thorac Surg. 2008;86(2):472-481. doi: 10.1016/j.athoracsur.2008.04.046

22.Zakai SB, Khan SU, Rabbi F, et al. Effects of mitral valve replacement with and without chordal preservation on cardiac function: early and mid-term results [J]. J Ayub Med Coll Abbottabad. 2010;22(1):91-96.

23. Guo Yong, He Yihua, Li Zhian, et al. Ultrasound evaluation of the effects of different mitral valve replacement on left ventricular structure and systolic function [J].Chinese Medical Ultrasound Journal: Electronic Edition. 2011;08 (2):30-33.

24. García FR, Vázquez A, Peláez AG, et al. Factors for development of late significant tricuspid regurgitation after mitral valve replacement: the impact of subvalvular preservation [J]. European journal of cardiothoracic surgery. 2011;39(6):866-874.

25.Xuan Hai, Shi Kaihu, Xu Shengsong, et al. Comparison of cardiac function after mitral valve replacement with preservation of total or posterior subvalvular structures in patients over 65 years old [J]. Journal of Jinan University (Natural Science and Medicine Edition). 2012, 33(4):426-428. 
26. Liang Ke, Li Shuangqi, Xie Rui. Comparison of cardiac function after different mitral valve replacement procedures [J]. Modern Hospital. 2012;12(8):35-36.

27. Chen L, Chen B, Hao J, et al. Complete preservation of the mitral valve apparatus during mitral valve replacement for rheumatic mitral regurgitation in patients with an enlarged left ventricular chamber [J]. Heart Surgery Forum. 2013;16(3):E137-E143. doi: 10.1532/ HSF98.20121128

28. Ozdemir AC, Emrecan B, Baltalarli A. Bileaflet versus PosteriorLeaflet-Only Preservation in Mitral Valve Replacement [J]. Tex Heart Inst J. 2014;41(2):165-169. doi: 10.14503/THIJ-13-3164

29. Roshanali F, Mandegar M HH, \& Moradi B. 140comparison between posterior leaflet and complete preservation versus complete resection of the subvalvular apparatus during mitral valve replacement in rheumatic patients with a "stenosis-dominant" valve. Interactive Cardiovascular \& Thoracic Surgery. 2014.

30. Li Jiyong, Zhang Jianqun, Boping, et al. A comparative study of mitral valve replacement with different methods of preserving subvalvular structures [J]. Journal of Cardiopulmonary Vascular Disease. 2014;33(4):529-534
31.Zhang Yulong. Observation of cardiac function after mitral valve replacement with complete preservation of mitral valve and subvalvular structure [J]. Journal of Modern Integrated Chinese and Western Medicine. 2014;23(7):702-703.

32.Huang Xiaolong, Yang Liushan, Wu Xilin. Application effect of different methods of preserving subvalvular structures in mitral valve replacement [J]. Shandong Medicine. 2015(42):40-41.

33. Ren Fei, Han Tao, Yao Zuwu, et al. Application of maintaining mitral valve structural integrity in mitral valve replacement [J]. Journal of Fujian Medical University. 2016;50(1): 57-59.

34. Lin Longhui, Han Tao. Comparative analysis of mitral valve replacement with different preserved subvalvular structures [J]. International Medical and Health Report. 2017;23 (10):1475-1477.

35. SáMP, Escobar RR, Ferraz PE, et al. Complete versus partial preservation of mitral valve apparatus during mitral valve replacement: metaanalysis and meta-regression, of 1535 patients[J]. Eur J Cardiothorac Surg. 2013;44(5):905-912. 